Technical Note

\title{
Creation of Anatomically Correct and Optimized for 3D Printing Human Bones Models
}

\author{
Edgars Edelmers*(D), Dzintra Kazoka (D) and Mara Pilmane \\ Institute of Anatomy and Anthropology, Rīga Stradinš University, LV-1010 Riga, Latvia; \\ Dzintra.Kazoka@rsu.lv (D.K.); Mara.Pilmane@rsu.lv (M.P.) \\ * Correspondence: edgars.edelmers@rsu.lv
}

Citation: Edelmers, E.; Kazoka, D.; Pilmane, M. Creation of Anatomically Correct and Optimized for 3D Printing Human Bones Models. Appl. Syst. Innov. 2021, 4, 67. https:// doi.org/10.3390/asi4030067

Academic Editor: Christos Douligeris

Received: 3 August 2021

Accepted: 10 September 2021

Published: 13 September 2021

Publisher's Note: MDPI stays neutral with regard to jurisdictional claims in published maps and institutional affiliations.

Copyright: (C) 2021 by the authors. Licensee MDPI, Basel, Switzerland. This article is an open access article distributed under the terms and conditions of the Creative Commons Attribution (CC BY) license (https:// creativecommons.org/licenses/by/ $4.0 /)$.

\begin{abstract}
Educational institutions in several countries state that the education sector should be modernized to ensure a contemporary, individualized, and more open learning process by introducing and developing advance digital solutions and learning tools. Visualization along with 3D printing have already found their implementation in different medical fields in Pauls Stradinš Clinical University Hospital, and Rīga Stradinš University, where models are being used for prosthetic manufacturing, surgery planning, simulation of procedures, and student education. The study aimed to develop a detailed methodology for the creation of anatomically correct and optimized models for 3D printing from radiological data using only free and widely available software. In this study, only free and cross-platform software from widely available internet sources has been used- "Meshmixer", "3D Slicer", and "Meshlab". For 3D printing, the Ultimaker 5S 3D printer along with PLA material was used. In its turn, radiological data have been obtained from the "New Mexico Decedent Image Database". In total, 28 models have been optimized and printed. The developed methodology can be used to create new models from scratch, which can be used will find implementation in different medical and scientific fields—simulation processes, anthropology, 3D printing, bioprinting, and education.
\end{abstract}

Keywords: medical; segmentation; 3D; printing; radiology; Meshmixer; Slicer; Meshlab

\section{Introduction}

Three-dimensional (3D) printing (also known as additive manufacturing) is a process of creating physical objects from their geometrical representation in a digital file by the successive addition of different materials [1,2]. With cost-effective manufacturing for high productivity, 3D-printing technology has become more popular in medical education in recent years, and it is suitable for a variety of applications, including medical moulages or anatomical models for educational purposes [3]. The benefit of anatomical models is that they can provide educational opportunities to learners who may otherwise not have access to original specimens [4,5]. In addition, 3D printing is useful for anatomy teaching in creating anatomical models that are not available for sale or reflect real-life variability. Various created anatomical models can involve active student learning: from 3D scanning to working with a variety of 3D modeling software applications, to using 3D printers, and then preparing the final model [6]. The usage of 3D printed anatomical models is becoming not only just a tool for regular anatomical lectures and practical labs but is widely used by students and doctors in the clinical environment as well [7].

Nowadays, 3D printing is being actively used in engineering and educational fields thanks to its great flexibility and the ability to create objects with complex sophisticated structures [8]. Medical schools, hospitals, and healthcare institutions can use the 3D models to improve clinical evaluation for several pathologies as well as bring new medical devices to market. Some of the most common applications in the medical industry are preclinical medical device testing and medical training models. For example, the insertion of a central venous catheter has been improved by using anatomical training kits [9]. Additionally, 
organ models play an important role in many types of major surgical procedures as well as the education and communication outside of surgery [10]. Three-dimensional (3D) models can also be used for surgical planning prior to operation, such as neurosurgery [11].

The availability of $3 \mathrm{D}$ printers and improved segmentation algorithms have boosted the use of 3D printing in medicine, and this has led to an interest in many potential medical applications [12]. Models can be quickly adapted to a particular patient, quickly reshaped, and $3 \mathrm{D}$ printed. It provides a cheap alternative to general commercially available anatomical models. Thus, 3D printing can be used to teach anatomical structures [13]. It should be noted that there are still problems making this process available to wideranging users.

This work describes the methodology for creating a correct and ready-to-print anatomical model for using radiological data. The whole workflow starting from the obtaining of radiological data until the physical 3D model is described in a step-by-step manner, along with programs required for the creation 3D model.

\section{General Workflow}

This section describes how to proceed from radiological data (CT, ultrasonography, magnetic resonance tomography) to a ready 3D-printed model. The workflow is divided into three mandatory and two additional steps:

1. Main stages:
1.1 Segment the model from radiological data.
1.2 Edit and optimize the model.
1.3 Print the 3D model.

2. Additional stages:

2.1 Validation of model correctness.

2.2 Create a model library.

\subsection{Model Segmentation from a Radiological Data}

The first step is to acquire radiological data, which is followed by segmentation of the structure of interest. Segmentation is a process in which an image is divided into individual regions with structures of interest. It is used below to generate an exact computer model of the patient's organs. The segmentation process itself is based on the principle that each tissue type is characterized by a range of voxels with different intensities. Therefore, it is possible to distinguish different tissues and to define organ borders.

There are several commercials (for example, "Mimics" from "Materialize" company [14] or "Synopsys Simpleware" [15]) and free programs for image segmentation. In this work, only free and widely available software has been used while at the same time also using one internationally recognized software-“"3D Slicer" [16].

\subsection{Edit and Optimize a Model}

Image segmentation is followed by editing and optimization of the $3 \mathrm{D}$ model to avoid potential artifacts as well as optimizing the end size of the model and improving anatomical correctness.

There are several programs for working with 3D models, but the "Meshlab" [17] features more advantages as it allows precise control of every program instrument, mass editing, and checking multiple models at once. The other program is "Meshmixer" [18], which allows you to manipulate model morphology. The main benefits of these programs are an intuitive interface and good documentation.

Errors should be corrected during the repair phase before printing (duplicating points; duplicating faces; faces with zero areas; edges with faulty geometry (non-manifold); points with faulty geometry (non-manifold); vertex not referenced by a face; microparticles that do not form a surface, etc.) and anatomical inaccuracies that may occur in the process of segmentation. 
Depending on outgoing data (radiological study type, tomography settings) and segmentation, "digital noise" may occur, which may affect the quality of the model surfaces, making them uneven and with multiple artifacts. As a result, there is a need for smoothing.

In some cases, the final model can be made by combining different models.

\subsection{Model Correctness Validation}

To preserve the anatomical correctness of the model, it is compared with trusted literature sources. In addition, specialized as well as the certified medical virtual application can be used. A good example is the "Complete Anatomy" [19], which is a correct and userfriendly tool for working with anatomical models. "Complete Anatomy" is the world's most advanced educational three-dimensional (3D) anatomy platform created by "3D4Medical" from "Elsevier", which has been developing medical products since 2009 [20,21].

\subsection{Printing a 3D Model}

Special types of 3D printing technologies have been developed with different functions. This section provides an overview of the 3D printing technologies, but only some techniques are widely applied in the medical industry and most commonly used to create anatomical models. The main reasons are the specific fabrication process and raw material to meet the high-quality requirements [22]. Several researchers have been conducted aiming at studying the accumulation of residual stresses and strains during the material build-up at the end or during the fabrication process in these technologies [23]. For example, the potential advantage of fused deposition modeling (FDM) is that it offers fabricating prototypes, tooling, and functional parts without geometrical complexity limitations, but there are observed significant dimensional deviations of the model surfaces [24,25].

According to "The American Society for Testing and Materials" in the US (ISO/ASTM 52900), methods of 3D printing were standardized into seven groups, including the binding jetting, directed energy deposition, material extrusion, material jetting, powder bed fusion, sheet lamination, and vat photopolymerization [26,27]. The selection of the method will depend on the use and visual appearance of the replica, the properties of the materials, and the possibilities of the printer (e.g., cost, settings, print time, and volume) [28].

There are four common additive manufacturing techniques (extrusion-based printing [29], vat polymerization-based printing [30], droplet-based printing [31], and powderbased printing [32]) when it comes to printing anatomical models.

Extrusion-based printing is commonly referred to as fused deposition modeling (FDM) or fused filament fabrication (FFF) [33]. FDM is a mature technology that is based on the extrusion of thermoplastic or composite materials drawn through the hot extrusion head with one or multiple extrusion nozzles [34]. For fabricating complex devices with functional parts such as valves, lenses, and fluidic interconnects, in FDM is a widely used vat-polymerization-based printing technique [35]. It is based on light-curing resin material and light-selective hardening polymerization molding. The process, where droplets of liquid materials are ejected and polymerized throughout hundreds of jets, is a material jetting technology. By directed UV for designed structures, the polymerization occurs only selectively [36]. It includes aerosol jet printing (AJP), binder jet printing (BJP), and poly jet printing (PJP).

Powder-based 3D printing is a technique with excellent ability for customized fabrication with a variety of external shapes, internal structures, and porosities. Four common powder-based printing techniques are selective laser sintering (SLS), selective laser melting (SLM), direct metal laser sintering (DMLS), and electron beam melting (EBM) [37]. There exist differences in the printing process and product characters among these printing techniques that are based on localized heating to generate melted metallic powder. It would be used to fabricate the customized products.

These different 3D printing technologies have their benefits and disadvantages.

The most widespread is extrusion technology. The main disadvantage of this method is its low precision; in its turn, the main advantage is its low printing costs (necessary 
equipment, maintenance, and material costs) as well as being the most user-friendly 3Dprinting technology. Researchers have tested and concluded that several process parameters (layer thickness, extruding temperature, printing speed, retraction distance, etc.) have to be carefully tuned to accomplish the desired and successful 3D printing results, using the lower end of desktop fused filament fabrication (FFF) 3D printers, and there exist a lot of challenges [38].

In cases where high precision and quality are required, different photopolymerization technologies can be used.

\section{Materials and Methods}

Table 1 reflects the software that has been used in this work. It is important to highlight that all the mentioned programs can be easily downloaded at no cost; these are intended to be used solely for scientific purposes-not for clinical applications, as the programs are not certified for medical applications.

Table 1. The list of used software.

\begin{tabular}{ccc}
\hline Software & Version & Source \\
\hline Autodesk Meshmixer & 3.5 .474 & meshmixer.com (accessed on 1 March 2021) \\
3D Slicer & 4.11 .20210226 r29738 & slicer.org (accessed on 1 March 2021) \\
MeshLab & 2020.12 & meshlab.net (accessed on 1 March 2021) \\
Ultimaker Cura & 4.8 & ultimaker.com/software/ultimaker-cura (accessed on 1 March 2021) \\
\hline
\end{tabular}

The short representation of the methodology can be seen in Figure 1.

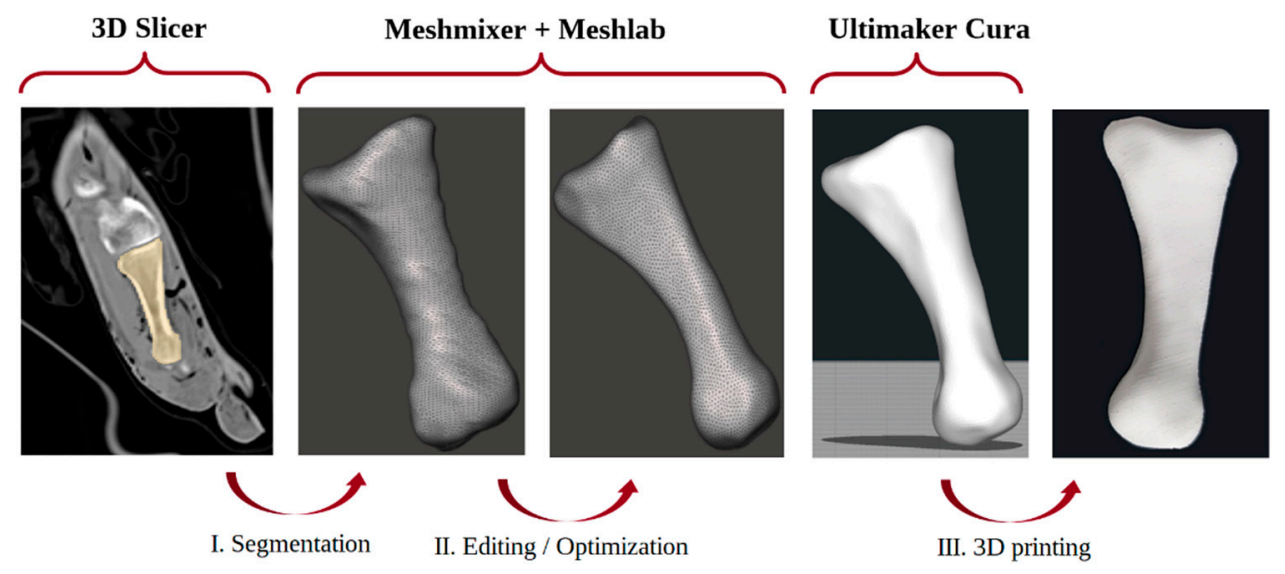

Figure 1. Graphical representation of the methodology.

\subsection{Protocol for the CT Exam to Be Used}

The CT scan used in this work was acquired from the "[858158-1] Facilitating forensic research in multiple fields using a unique compilated tomography dataset" "New Mexico Decedent Image Database") project [39].

The protocol for the CT scan was obtained from the "New Mexico Decedent Image Database" homepage (Table 2).

Table 2. Computed tomography protocol.

\begin{tabular}{cc}
\hline Parameter & Value \\
\hline $\mathrm{kVp}$ & $\mathrm{kVp} 120$ \\
$\mathrm{mAs}$ & $\mathrm{mAs} 200$ \\
Scan length & Scan length $800-1000 \mathrm{~mm}$ \\
Scan FOV & Scan FOV $500 \mathrm{~mm}$ \\
Pitch & Pitch 0.942 \\
Collimation & Collimation $16 \times 0.75$ \\
Rotation Time & Rotation Time $1.0 \mathrm{~s}$ \\
Matrix & Matrix 512 5512 \\
\hline
\end{tabular}


After the scan, the reconstruction was performed with the following technical parameters:

- $\quad 3 \mathrm{~mm} \times 3 \mathrm{~mm}$ soft tissue $=320$ images.

- $\quad 3 \mathrm{~mm} \times 3 \mathrm{~mm}$ bone $=320$ images.

- $1 \mathrm{~mm} \times 0.5 \mathrm{~mm}$ soft tissue $=1900$ images.

- $1 \mathrm{~mm} \times 0.5 \mathrm{~mm}$ bone $=1900$ images.

3.2. Segmentation Methodology I 3D Slicer

1. Launch the $3 D$ Slicer program.

2. Import CT data into the program.

- Set image contrast to ensure better visibility.

3. Use the instrument:

- "Volume Rendering"

Using the region of interest tool separate the segmentation region from any other structures.

4. Add a new segment using the tool:

- Segment Editor

Set up the Threshold tool.

Using the Scissors, Smooth, Draw, manually segment the required structure.

5. When completed segmentizing one structure, proceed to the second one by adding a new segment and repeat the segmentation procedure.

6. Export the completed segment or segments as a 3D model in the OBJ file format.

\subsection{Validation Methodology | Literature}

1. Check the correctness of anatomical structures using the literature [19-21].

2. For 3D models whose structures do not correspond to normal human anatomy, make the necessary adjustments using the editing methodology.

\subsection{Editing Methodology | Meshmixer}

1. Launch the "Meshmixer" program.

2. Import the 3D model (or models if there is a need to combine multiple models into a single model, such as putting a foot from individual bones) into the program.

3. Use instruments to make necessary adjustments:

- $\quad$ Select

\section{Edit}

- $\quad$ Erase \& Fill

- Discard

- Discard

- Brushes

- Make Solid

- Add Tube

4. To combine multiple models into one, select all models in the "Object Browser" section by holding the "Shift" button on the keyboard and select all the models from the list by clicking on them with a cursor; then, apply the "Combine" tool.

5. Export the 3D model as an OBJ file.

\subsection{Optimization Methodology|MeshLab + Meshmixer}

1. Launch the "MeshLab" program.

2. Import the 3D model into the program.

3. Remove artifacts using tools:

- Remove duplicated faces 
- $\quad$ Remove duplicated vertex

- Remove Zero Area faces

- Repair Non-Manifold Edges by removing faces

- Repair Non-Manifold Verticles by Splitting

Vertex Displacement Ration $=0$

- Remove Unreported Vertex

- $\quad$ Remove Solved Attachments (wrt Diameter)

Max diameter of isolated attachments (\%) $=10$

Remove Unreported Vertex $=\mathrm{ON}$

4. Export 3D model as an OBJ file.

5. Launch the "Meshmixer" program.

6. Import the 3D model into the application.

7. Close micro-holes (Boundary edge type error) by reconstructing the mesh surface using the instrument:

- Inspector

Hole Fill Mode $=$ Smooth Fill

Small Thresh $=0.01 \mathrm{~mm}$

8. Optimize the model polygon mesh to minimize the size of the file (3D model) using the tool:

- Remesh

$$
\begin{aligned}
& \text { Remesh Mode = Relative Density } \\
& \text { Density }(\%)=0 \\
& \text { Regularity }=100 \\
& \text { Iterations }=10 \\
& \text { Transition }(\mathrm{mm})=0 \\
& \text { Smooth Group Boundaries = ON } \\
& \text { Boundary Mode = Refined Boundary }
\end{aligned}
$$

9. Smooth the 3D models surface if needed:

- Select

Deform

- Smooth

- $\quad$ Smoothing Type $=$ Shape Preserving

- $\quad$ Smoothing = 1

- $\quad$ Smoothing Scale $=4$ (decrease or increase as needed)

- Constraint Rings = 3

10. Export the 3D model as an OBJ file.

\subsection{Validation Methodology I Literature}

1. Check the correctness of anatomical structures using literature [19-21].

2. For 3D models whose structures do not correspond to normal human anatomy, make the necessary adjustments using the editing methodology.

\subsection{D Printing | Cura Ultimaker}

1. Launch the "Ultimaker Cura" program.

2. Import the 3D model into the program.

3. Create a profile (based on the built-in profile "Visual" with a slice thickness of 0.1 $\mathrm{mm}$ with further modification and optimization to maximize quality, durability, and precision); the main material for the model is PLA, in it's turn for the support structures the PVA is being used.

- Shell 


\section{Wall Line Count $=10$}

Top/Bottom Pattern $=$ Concentric

Z Seam Alignment $=$ Random

- Infill

$\bigcirc \quad$ Density $(\%)=30$

$\bigcirc \quad$ Infill Pattern $=$ Gyroid

- Build Plate Adhesion

Build Plate Adhesion Type $=$ Brim

Build Plate Adhesion Extruder $=$ Extruder $2(P V A)$

4. Optimize models' position using the "Auto-Orientation" extension from the "Ultimaker Cura" library (Marketplace).

5. Start the printing process.

6. Remove support structures from the model by immersing the model in water $\left(25^{\circ} \mathrm{C}\right)$ for $24 \mathrm{~h}$.

7. Remove the 3D model from the container with water and allow it to dry.

8. Check the correctness of the 3D printed model by comparing it to the virtual original.

\section{Results}

All 28 foot bones were segmented using the "3D Slicer" application following the developed segmentation methodology. Each bone was segmented, processed, and 3D printed separately.

A total of 28 anatomical 3D models were created by segmenting the relevant structures from 763 CT images.

The validation of 28 models' anatomical correction with the help of the literature [19-21] was performed. At this stage, it is necessary to decide whether additional model editing is required. In case of a positive result, adjustments are made by the editing methodology in the "Meshmixer" program.

A total of 19 models were modified by "Meshmixer" to retain anatomical correctness according to normal human anatomy.

The next step is the optimization of the models, which begins with the correction of errors and artifacts in the "Meshlab" program (duplicating points; duplicating faces; faces with zero areas; edges with faulty geometry (non-manifold); points with faulty geometry (non-manifold); vertex not referenced by a face; microparticles that do not form a surface).

This is followed by the optimization (simplification) of a polygon mesh (Figure 2) to improve the visual aspect of the model (for demonstration in a virtual library during classes), make the mesh suitable for further manipulation (deformation, cutting, modeling, etc.), reduce the model size as well as ensure printability of the model on an FDM-type printer.

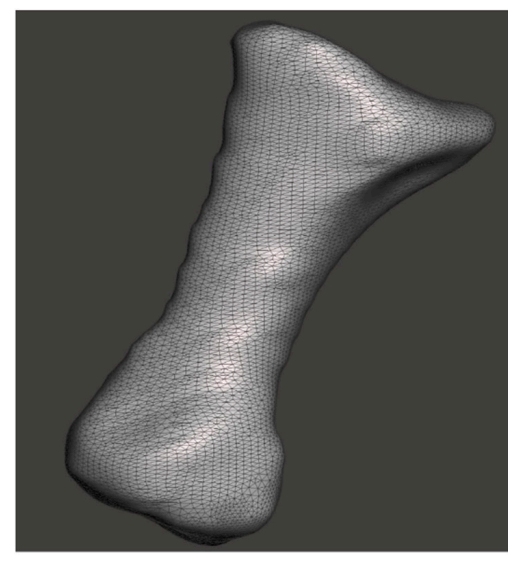

(a)

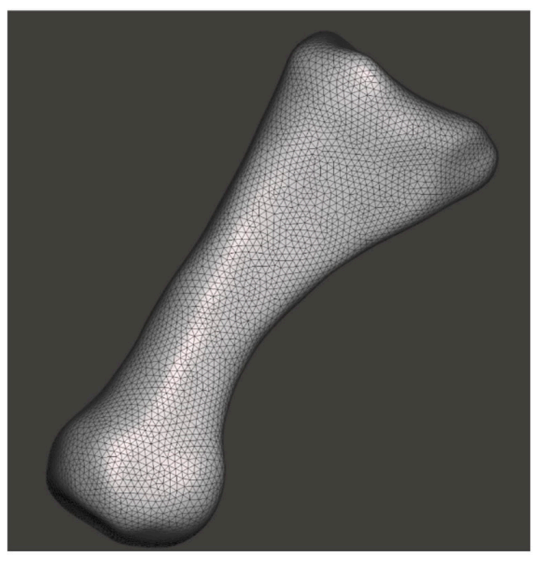

(b)

Figure 2. Os metatarsus primus 3D model original polygon mesh (a) and model with edited and optimized polygon mesh (b). 
A total of 28 models were optimized to correct the errors and artifacts that occurred during the segmentation process (Figure 3).

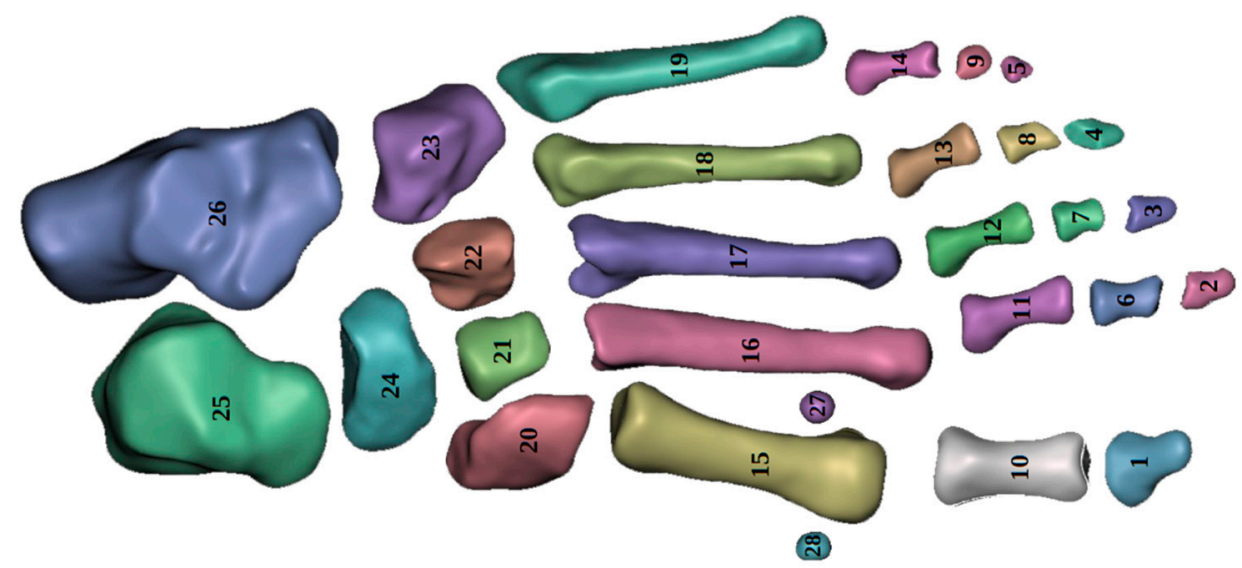

Figure 3. The structure of human foot 3D model. 1-Phalanx distalis hallucis, 2-Phalanx distalis digiti pedis secundi, 3-Phalanx distalis digiti pedis tertii, 4-Phalanx distalis digiti pedis quarti, 5-Phalanx distalis digiti pedis minimi, 6-Phalanx media digiti pedis secundi, 7-Phalanx media digiti pedis tertii, 8-Phalanx media digiti pedis quarti, 9-Phalanx media digiti pedis minii, 10_Phalanx proximalis hallucis, 11-Phalanx proximalis digiti pedis secundi, 12-Phalanx proximalis pedis digiti tertii, 13-Phalanx proximalis digiti pedis quarti, 14-Phalanx proximalis digiti pedis minimi, 15-Os metatarsus primus, 16-Os metatarsus secundus, 17-Os metatarsus tertius, 18-Os metatarsus quartus, 19-Os metatarsus quintus, 20-Os cuneiforme mediale, 21-Os cuneiforme intermedium, 22-Os cuneiforme laterale, 23-Os cuboideum, 24-Os naviculare, 25-Talus, 26-Calcaneus, 27/28-Os sesamoideum.

The next step is the validation of models' anatomical correction with the help of the literature [19-21]. At this stage, it is necessary to decide whether additional model editing is required. In case of a positive result, adjustments are made following the editing methodology in the "Meshmixer" program.

The final step is 3D printing, which takes place in accordance with the 3D printing methodology (partly shown in Figure 4), while the printing process itself uses a 5S 3D extrusion-type printer from Ultimaker company with the following parameters:

Nozzle diameter: $0.4 \mathrm{~mm}$,

Layer Height: $0.1 \mathrm{~mm}$,

Print Speed: $70 \mathrm{~mm} / \mathrm{s}$,

Temperature: $200{ }^{\circ} \mathrm{C}$,

Build Plate Temperature: $60^{\circ} \mathrm{C}$,

Fans Speed: $100 \%$.

The printing process took $44 \mathrm{~h}$ and $15 \mathrm{~min}$; during the process, $122 \mathrm{~g}$ of "PLA/PHA Semi-Matte White" and $45 \mathrm{~g}$ of "Ultimaker PVA" were used.

During the post-process, all models were immersed in water $\left(24^{\circ} \mathrm{C}\right)$ for $24 \mathrm{~h}$ to dissolve support structures. After removal from the water, the models were left to dry for $24 \mathrm{~h}$ at room temperature $\left(24^{\circ} \mathrm{C}\right)$. The final stage is to compare the $3 \mathrm{D}$ printed model to the virtual one. The final result is shown in Figure 5.

In total, 723 radiological images have been used, 28 models from segmented areas have been created, 28 models have been checked, 19 models have been modified, and 28 models have been optimized and printed. 


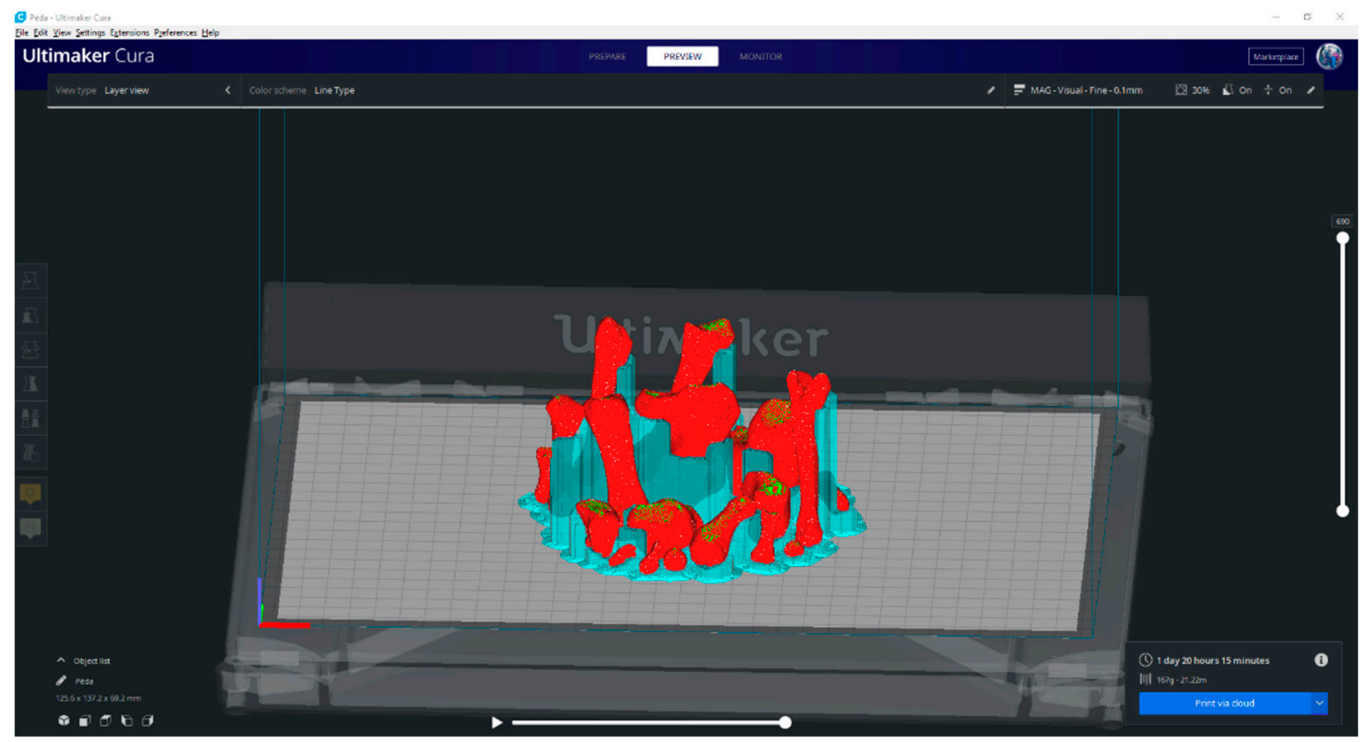

Figure 4. The graphical user interface of the "Ultimaker Cura" program. Individually positioned bones of the foot $3 \mathrm{D}$ model are shown in red color, supporting structures are shown in turquoise color.

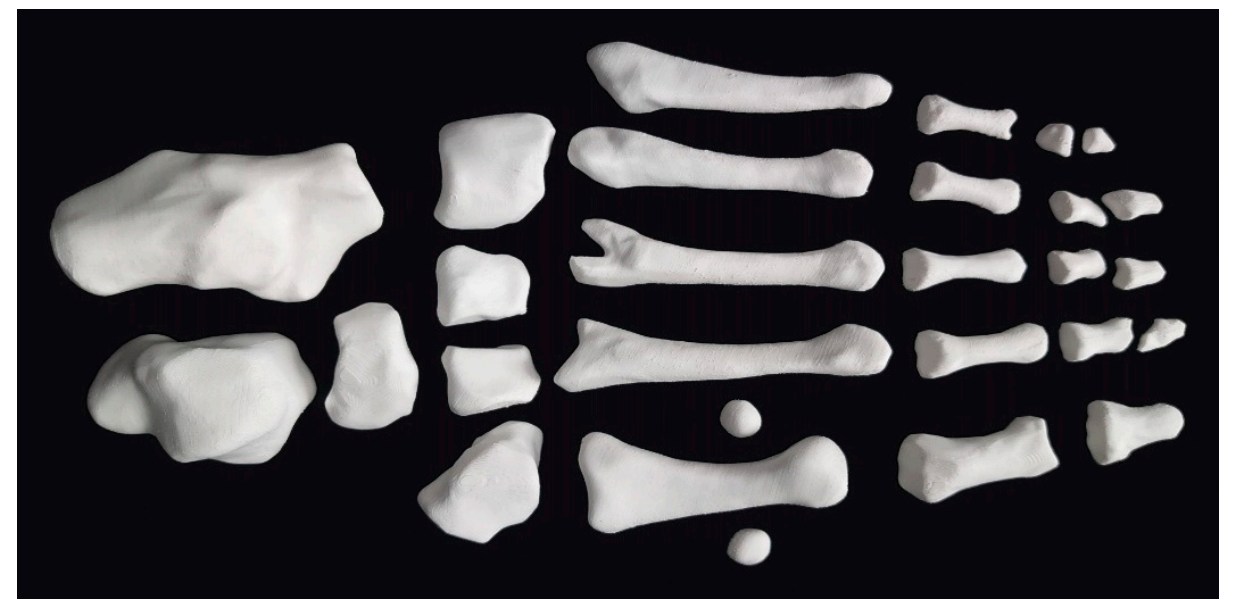

Figure 5. Three-dimensional (3D) printed model of human foot bones.

\section{Discussion}

Today, using 3D printers especially for medical applications is a challenging task, as it involves special knowledge about human anatomy and the structures. New materials, technologies, and segmentation techniques require regular testing to be integrated effectively in the education, engineering, and clinical environment. Nowadays, for the creation and transplantation of different tissues, 3D bioprinting has been used in the scientific and medical fields [40]. Different materials and fabrication methods (traditional and free-form) have been investigated for use in other medical fields or regenerative tissue engineering (TE), for example for creating scaffolds in bone tissue [41]. The 3D-printed tissue scaffolds can be constructed with a very high level of accuracy and repeatability of predetermined forms and structures, and these designs can be used for the comparison of their mechanical properties [42]. In addition, scaffold structures must be related to several important criteria, for example, the case-specific internal geometry design with a controlled porosity percentage [43]. In addition, 3D technology has shown great potential as an educational tool in areas such as anatomical modeling and images, and it can be used to scan the human body with magnetic resonance imaging or with computed tomography scans [44,45].

Several models can be replicated in large quantities for students to be used during practical classes. A range of human body models has already been developed for different 
applications in both educational and medical fields. Our study states that 3D human anatomical models can support the study process in the absence of cadaveric material, for example during remote classes with students. Knowledge of skeletal anatomy is a basic educational component for every medical student [46]. Bones are very important parts of the human body and provide structural support to the system, and due to this fact, the bone system has been chosen as the first system that shall be digitalized. Different studies report how 3D printing allows the creation of reproductions of dissected human cadavers and different anatomical specimens for teaching purposes and surgical training $[47,48]$.

Three-dimensional (3D) printing creates opportunities for integrating science, engineering, technology, and mathematics (STEM) with other disciplines [49]. The integration of 3D technology, in different forms, allows for the visualization of new creative possibilities that the STEM field has to offer. Therefore, many teachers are focused on using 3D printing, including it at all school levels, from primary through to secondary (high school). When learners can engage with STEM concepts from a young age, STEM education aims to adopt a new learning approach, and it goes beyond the ability to remember facts and procedures [50]. At the third level of education, there are greater possibilities to teach students how 3D printing technology works. Nowadays, many third-level universities or technical colleges incorporate 3D printing modules and projects into applied sciences, engineering, and other courses [51].

It is believed that this technology will be more integrated into undergraduate anatomy education [52]. At the same time, the creation of anatomical models to fully understand the anatomical relationships between different structures will be important for studying normal and pathological anatomy [53]. These models can be manufactured as functional multi-layered units and offer rich possibilities for sectional and/or reduced anatomy [54].

To assess the quality of these innovative resources as anatomy educational tools, the accuracy of all printed models should be compared with original specimens. It seems that some of the available 3D printed products cannot be used in work with students due to the bad precision and different anatomical inaccuracies. Many studies describe the experience of the use of such teaching techniques as a pre-test, live tests, and post-test surveys [55,56]. Nevertheless, the implementation of 3D models in anatomy education shows promising outcomes [57].

The 3D model search includes special requirements including the quality of structures, high resolution, and accurate color reproductions. This process can be very complicated, and it can take a lot of time.

Furthermore, anatomically correct models can be computer-generated from medical image data. Computational modeling is common in many areas of science and engineering, only recently have advances in experimental techniques and medical imaging allowed this tool to be applied in cardiac surgery [58]. A computational heart model can provide additional information that is not easily measurable in experiments [59]. Forces are applied to any specific spot on the extrapolated 3D model to calculate stresses and strains in different areas of the model. For example, in vivo evaluation of the aortic wall strain was simple, fast, and it could be used to develop a rupture potential criterion based on the aortic aneurysm extensibility [60]. Furthermore, wall shear stress (WSS) has an important implication on bicuspid aortopathy, and computational flow analyses were used to estimate this parameter and aortic geometry with comparison to standard geometric reconstructions obtained by computed-tomography angiography (CTA) scans [61].

The creation of the online 3D model database may encourage educators to easily manufacture these models for specific educational purposes [62]. Most of these databases provide the function of a text-based model search for keywords. The most crucial part of the fabrication of a qualitative 3D model is to obtain high-resolution CT data of the organ [63]. Unfortunately, the segmentation process leads to the creation of different kinds of errors and artifacts (non-manifold objects, duplicated vertex, etc.). Verification of all printed models' accuracy is an essential step in 3D model creation. Full-reference image visual quality metrics are widely used at different stages of digital image processing [64]. 
Once the model is finished, it can be explored in 3D, measured, formatted, and manipulated to gain an all-encompassing understanding of the anatomy.

Further, the possibility to manipulate with models in three-dimensional space is important for medical students, clinicians, and surgeons [65-67] to better understand anatomical structures. Different patient-specific 3D printed models can allow specialists to review both normal and abnormal anatomical structures. In addition, the interpretation of complex three-dimensional spatial relationships in cross-sectional and radiological images can enhance student's interpretation of cross-sectional anatomy [68-70].

Nowadays, 3D objects that are based on actual image data of human bodies are more and more used to teach human anatomy, but some authors report that to efficiently create 3D-printed anatomic models and later use them safely for medical purposes, professionals and radiologists have to understand the methodology and process of converting medical imaging data into digital models [71-73].

\section{Conclusions}

The creation of anatomically accurate reproductions of human bones offers many advantages as it allows the rapid production of multiple copies at any size scale and should be suitable for any teaching facility. Three-dimensional (3D)-printed bones can be successfully applied in anatomy education at Rīga Stradinš University.

During this study, a methodology for transforming, segmenting, and processing human bone Digital Imaging and Communications in Medicine (DICOM) images has been developed that allows the creation (segment) of 3D models from radiological data. Only free and widely available programs have been used to ensure results reproducibility and allow students as well as medical and education specialists to allow access to this innovative method of medical 3D model creation. The application of 3D anatomical models will further ramify and expand into other study courses. Moreover, the 3D printing of the human bones will soon involve other anatomical structures, particularly those that are difficult to detect and manipulate. It is planned that created models of the bones will also be utilized in the pathology field of human anatomy.

Furthermore, alternative printers and techniques will be explored, and our proposed methods will be improved and used in work with students and incorporated in a new direction-education science at the Rìga Stradinš University. This technique can enrich the medical education process, support specialists in the clinical field in complicated cases and with limited resources, and in the end boost the research in an interdisciplinary field where medicine meets computed sciences. The mentioned methodology can be enhanced in terms of visual quality and precision by replacing the FDM-type printer with a vat polymerization (SLA or DLP) 3D printer.

Author Contributions: Conceptualization, E.E.; methodology, E.E.; investigation, E.E. and D.K.; writing — original draft preparation, E.E.; writing—review and editing, E.E., M.P. and D.K. All authors have read and agreed to the published version of the manuscript.

Funding: This research received no external funding.

Institutional Review Board Statement: Not applicable.

Informed Consent Statement: The approval from RSU Ethics Committee has been received Nr. 2-3/217.

Data Availability Statement: Data are contained within the article.

Conflicts of Interest: The authors declare no conflict of interest. 


\section{References}

1. Shahrubudin, N.; Lee, T.C.; Ramlan, R. An Overview on 3D Printing Technology: Technological, Materials, and Applications. Procedia Manuf. 2019, 35, 1286-1296. [CrossRef]

2. Thomas, D.B.; Hiscox, J.D.; Dixon, B.J.; Potgieter, J. 3D Scanning and Printing Skeletal Tissues for Anatomy Education. J. Anat. 2016, 229, 473-481. [CrossRef] [PubMed]

3. Lim, K.H.A.; Loo, Z.Y.; Goldie, S.J.; Adams, J.W.; McMenamin, P.G. Use of 3D Printed Models in Medical Education: A Randomized Control Trial Comparing 3D Prints versus Cadaveric Materials for Learning External Cardiac Anatomy: Use of 3D Prints in Medical Education. Am. Assoc. Anat. 2016, 9, 213-221. [CrossRef]

4. Pujol, S.; Baldwin, M.; Nassiri, J.; Kikinis, R.; Shaffer, K. Using 3D Modeling Techniques to Enhance Teaching of Difficult Anatomical Concepts. Acad. Radiol. 2016, 23, 507-516. [CrossRef]

5. Ngo, T.D.; Kashani, A.; Imbalzano, G.; Nguyen, K.T.Q.; Hui, D. Additive Manufacturing (3D Printing): A Review of Materials, Methods, Applications and Challenges. Compos. Part B Eng. 2018, 143, 172-196. [CrossRef]

6. AbouHashem, Y.; Dayal, M.; Savanah, S.; Štrkalj, G. The Application of 3D Printing in Anatomy Education. Med. Educ. Online 2015, 20, 29847. [CrossRef]

7. Kazoka, D.; Pilmane, M.; Edelmers, E. Facilitating Student Understanding through Incorporating Digital Images and 3D-Printed Models in a Human Anatomy Course. Educ. Sci. 2021, 11, 380. [CrossRef]

8. Li, K.H.C.; Kui, C.; Lee, E.K.M.; Ho, C.S.; Wong, S.H.; Wu, W.; Wong, W.T.; Voll, J.; Li, G.; Liu, T.; et al. The Role of 3D Printing in Anatomy Education and Surgical Training: A Narrative Review. MedEdPublish 2017, 6. [CrossRef]

9. Ford, S.; Minshall, T. Invited Review Article: Where and How 3D Printing Is Used in Teaching and Education. Addit. Manuf. 2019, 25, 131-150. [CrossRef]

10. Evans, L.V.; Dodge, K.L.; Shah, T.D.; Kaplan, L.J.; Siegel, M.D.; Moore, C.L.; Hamann, C.J.; Lin, Z.; D’Onofrio, G. Simulation Training in Central Venous Catheter Insertion: Improved Performance in Clinical Practice. Acad. Med. 2010, 85, 1462-1469. [CrossRef] [PubMed]

11. Müller, A.; Krishnan, K.G.; Uhl, E.; Mast, G. The Application of Rapid Prototyping Techniques in Cranial Reconstruction and Preoperative Planning in Neurosurgery. J. Craniofacial Surg. 2003, 14, 899-914. [CrossRef]

12. Trace, A.P.; Ortiz, D.; Deal, A.; Retrouvey, M.; Elzie, C.; Goodmurphy, C.; Morey, J.; Hawkins, C.M. Radiology's Emerging Role in 3-D Printing Applications in Health Care. J. Am. Coll. Radiol. 2016, 13, 856-862.e4. [CrossRef]

13. Rengier, F.; Mehndiratta, A.; von Tengg-Kobligk, H.; Zechmann, C.M.; Unterhinninghofen, R.; Kauczor, H.-U.; Giesel, F.L. 3D Printing Based on Imaging Data: Review of Medical Applications. Int. J. CARS 2010, 5, 335-341. [CrossRef] [PubMed]

14. Materialise Mimics. Available online: https:/ /www.materialise.com (accessed on 27 August 2021).

15. Synopsys Simpleware. Available online: https://www/simpleware.com (accessed on 27 August 2021).

16. Giannopoulos, A.A.; Mitsouras, D.; Yoo, S.-J.; Liu, P.P.; Chatzizisis, Y.S.; Rybicki, F.J. Applications of 3D Printing in Cardiovascular Diseases. Nat. Rev. Cardiol. 2016, 13, 701-718. [CrossRef] [PubMed]

17. Cignoni, P.; Ranzuglia, M.; Corsini, G. MeshLab: An Open-Source 3D Mesh Proceeding System. European Association for Computer Graphics. In Eurographics Italian Chapter Proceedings, Proceedings of the Sixth Eurographics Italian Chapter Conference, Salerno, Italy, 2-4 July 2008; Scarano, V., Ed.; Eurographics Association: Aire-la-Ville, Switzerland, 2008; pp. 129-136.

18. Qin, Y.; Qi, Q.; Scott, P.J.; Jiang, X. Status, Comparison, and Future of the Representations of Additive Manufacturing Data. Comput. Aided Des. 2019, 111, 44-64. [CrossRef]

19. Motsinger, S.K. Complete Anatomy. JMLA 2020, 108. [CrossRef]

20. Nair, R.R.; Lindsey, A. Student Perception on Integration of 3D Complete Anatomy Software Application in Medical Curriculum. FASEB J. 2020, 34 (Suppl. S1), 1. [CrossRef]

21. 3D4Medical. Complete Anatomy. 3D4Medical. Available online: https:/ /3d4medical.com (accessed on 27 August 2021).

22. Fan, D.; Li, Y.; Wang, X.; Zhu, T.; Wang, Q.; Cai, H.; Li, W.; Tian, Y.; Liu, Z. Progressive 3D Printing Technology and Its Application in Medical Materials. Front. Pharmacol. 2020, 11, 122. [CrossRef] [PubMed]

23. Kantaros, A.; Karalekas, D. FBG Based In Situ Characterization of Residual Strains in FDM Process. In Residual Stress, Thermomechanics \& Infrared Imaging, Hybrid Techniques and Inverse Problems; Rossi, M., Sasso, M., Connesson, N., Singh, R., DeWald, A., Backman, D., Gloeckner, P., Eds.; Conference Proceedings of the Society for Experimental Mechanics Series; Springer International Publishing: Cham, Switzerland, 2014; Volume 8, pp. 333-337. [CrossRef]

24. Boschetto, A.; Bottini, L. Design for Manufacturing of Surfaces to Improve Accuracy in Fused Deposition Modeling. Robot. Comput. Integr. Manuf. 2016, 37, 103-114. [CrossRef]

25. Kantaros, A.; Karalekas, D. Fiber Bragg Grating Based Investigation of Residual Strains in ABS Parts Fabricated by Fused Deposition Modeling Process. Mater. Des. 2013, 50, 44-50. [CrossRef]

26. Hodgdon, T.; Danrad, R.; Patel, M.J.; Smith, S.E.; Richardson, M.L.; Ballard, D.H.; Ali, S.; Trace, A.P.; DeBenedectis, C.M.; Zygmont, M.E.; et al. Logistics of Three-Dimensional Printing. Acad. Radiol. 2018, 25, 40-51. [CrossRef]

27. Horn, T.J.; Harrysson, O.L.A. Overview of Current Additive Manufacturing Technologies and Selected Applications. Sci. Prog. 2012, 95, 255-282. [CrossRef] [PubMed]

28. Aimar, A.; Palermo, A.; Innocenti, B. The Role of 3D Printing in Medical Applications: A State of the Art. J. Healthc. Eng. 2019, 2019, 1-10. [CrossRef] [PubMed] 
29. Taylor, S.L.; Ibeh, A.J.; Jakus, A.E.; Shah, R.N.; Dunand, D.C. NiTi-Nb Micro-Trusses Fabricated via Extrusion-Based 3D-Printing of Powders and Transient-Liquid-Phase Sintering. Acta Biomater. 2018, 76, 359-370. [CrossRef] [PubMed]

30. Stefaniak, A.B.; Bowers, L.N.; Knepp, A.K.; Luxton, T.P.; Peloquin, D.M.; Baumann, E.J.; Ham, J.E.; Wells, J.R.; Johnson, A.R.; LeBouf, R.F.; et al. Particle and Vapor Emissions from Vat Polymerization Desktop-Scale 3-Dimensional Printers. J. Occup. Environ. Hyg. 2019, 16, 519-531. [CrossRef]

31. Graham, A.D.; Olof, S.N.; Burke, M.J.; Armstrong, J.P.K.; Mikhailova, E.A.; Nicholson, J.G.; Box, S.J.; Szele, F.G.; Perriman, A.W.; Bayley, H. High-Resolution Patterned Cellular Constructs by Droplet-Based 3D Printing. Sci. Rep. 2017, 7, 7004. [CrossRef] [PubMed]

32. Shirazi, S.F.S.; Gharehkhani, S.; Mehrali, M.; Yarmand, H.; Metselaar, H.S.C.; Adib Kadri, N.; Osman, N.A.A. A Review on Powder-Based Additive Manufacturing for Tissue Engineering: Selective Laser Sintering and Inkjet 3D Printing. Sci. Technol. Adv. Mater. 2015, 16, 033502. [CrossRef]

33. Placone, J.K.; Engler, A.J. Recent Advances in Extrusion-Based 3D Printing for Biomedical Applications. Adv. Healthc. Mater. 2018, 7, 1701161. [CrossRef]

34. Paxton, N.; Smolan, W.; Böck, T.; Melchels, F.; Groll, J.; Jungst, T. Proposal to Assess Printability of Bioinks for Extrusion-Based Bioprinting and Evaluation of Rheological Properties Governing Bioprintability. Biofabrication 2017, 9, 044107. [CrossRef] [PubMed]

35. Carve, M.; Wlodkowic, D. 3D-Printed Chips: Compatibility of Additive Manufacturing Photopolymeric Substrata with Biological Applications. Micromachines 2018, 9, 91. [CrossRef]

36. Revilla-León, M.; Özcan, M. Additive Manufacturing Technologies Used for Processing Polymers: Current Status and Potential Application in Prosthetic Dentistry: Polymer Additive Manufacturing for Prosthodontics. J. Prosthodont. 2019, 28, 146-158. [CrossRef]

37. Brunello, G.; Sivolella, S.; Meneghello, R.; Ferroni, L.; Gardin, C.; Piattelli, A.; Zavan, B.; Bressan, E. Powder-Based 3D Printing for Bone Tissue Engineering. Biotechnol. Adv. 2016, 34, 740-753. [CrossRef]

38. Antreas, K.; Piromalis, D. Employing a Low-Cost Desktop 3D Printer: Challenges, and How to Overcome Them by Tuning Key Process Parameters. Mechanics 2021, 10, 11-19. [CrossRef]

39. Edgar, H.J.H.; Berry, S.D.; Moes, E.; Adolphi, N.L.; Bridges, P.; Nolte, K.B. New Mexico Decedent Image Database; Office of the Medical Investigator, University of New Mexico: Albuquerque, NM, USA, 2020. [CrossRef]

40. Murphy, S.V.; Atala, A. 3D Bioprinting of Tissues and Organs. Nat. Biotechnol. 2014, 32, 773-785. [CrossRef]

41. Wubneh, A.; Tsekoura, E.K.; Ayranci, C.; Uludağ, H. Current state of fabrication technologies and materials for bone tissue engineering. Acta Biomater. 2018, 80, 1-30. [CrossRef]

42. Kantaros, A.; Chatzidai, N.; Karalekas, D. 3D Printing-Assisted Design of Scaffold Structures. Int. J. Adv. Manuf. Technol. 2016, 82, 559-571. [CrossRef]

43. Kantaros, A.; Piromalis, D. Fabricating Lattice Structures via 3D Printing: The Case of Porous Bio-Engineered Scaffolds. Appl. Mech. 2021, 2, 289-302. [CrossRef]

44. Ye, Z.; Dun, A.; Jiang, H.; Nie, C.; Zhao, S.; Wang, T.; Zhai, J. The Role of 3D Printed Models in the Teaching of Human Anatomy: A Systematic Review and Meta-Analysis. BMC Med. Educ. 2020, 20, 335. [CrossRef]

45. Vaccarezza, M.; Papa, V. 3D Printing: A Valuable Resource in Human Anatomy Education. Anat. Sci. Int. 2015, 90, 64-65. [CrossRef]

46. Wu, A.-M.; Wang, K.; Wang, J.-S.; Chen, C.-H.; Yang, X.-D.; Ni, W.-F.; Hu, Y.-Z. The Addition of 3D Printed Models to Enhance the Teaching and Learning of Bone Spatial Anatomy and Fractures for Undergraduate Students: A Randomized Controlled Study. Ann. Transl. Med. 2018, 6, 403. [CrossRef]

47. McMenamin, P.G.; Quayle, M.R.; McHenry, C.R.; Adams, J.W. The Production of Anatomical Teaching Resources Using ThreeDimensional (3D) Printing Technology: 3D Printing in Anatomy Education. Am. Assoc. Anat. 2014, 7, 479-486. [CrossRef]

48. Langridge, B.; Momin, S.; Coumbe, B.; Woin, E.; Griffin, M.; Butler, P. Systematic Review of the Use of 3-Dimensional Printing in Surgical Teaching and Assessment. J. Surg. Educ. 2018, 75, 209-221. [CrossRef] [PubMed]

49. Lin, K.-Y.; Hsiao, H.-S.; Chang, Y.-S.; Chien, Y.-H.; Wu, Y.-T. The Effectiveness of Using 3D Printing Technology in STEM Project-Based Learning Activities. EURASIA J. Math. Sci. Technol. Educ. 2018, 14, em1633. [CrossRef]

50. Fleer, M. Working Technologically: Investigations into How Young Children Design and Make During Technology Education. Int. J. Technol. Des. Educ. 2000, 10, 43-59. [CrossRef]

51. Cohen, B. Teaching STEM after School: Correlates of Instructional Comfort. J. Educ. Res. 2018, 111, 246-255. [CrossRef]

52. Keenan, I.; Awadh, A.B. Integrating 3D Visualisation Technologies in Undergraduate Anatomy Education. Adv. Exp. Med. Biol. 2019, 1120, 39-53. [CrossRef] [PubMed]

53. Smith, C.F.; Tollemache, N.; Covill, D.; Johnston, M. Take Away Body Parts! An Investigation into the Use of 3D-Printed Anatomical Models in Undergraduate Anatomy Education. Am. Assoc. Anat. 2018, 11, 44-53. [CrossRef]

54. Smith, M.L.; Jones, J.F.X. Dual-Extrusion 3D Printing of Anatomical Models for Education: Two Materials 3D Printing in Anatomy. Am. Assoc. Anat. 2018, 11, 65-72. [CrossRef]

55. Garas, M.; Vaccarezza, M.; Newland, G.; McVay-Doornbusch, K.; Hasani, J. 3D-Printed Specimens as a Valuable Tool in Anatomy Education: A Pilot Study. Ann. Anat. Anat. Anz. 2018, 219, 57-64. [CrossRef] 
56. Chen, S.; Pan, Z.; Wu, Y.; Gu, Z.; Li, M.; Liang, Z.; Zhu, H.; Yao, Y.; Shui, W.; Shen, Z.; et al. The Role of Three-Dimensional Printed Models of Skull in Anatomy Education: A Randomized Controlled Trail. Sci. Rep. 2017, 7, 575. [CrossRef] [PubMed]

57. Chytas, D.; Johnson, E.O.; Piagkou, M.; Tsakotos, G.; Babis, G.C.; Nikolaou, V.S.; Markatos, K.; Natsis, K. Three-Dimensional Printing in Anatomy Teaching: Current Evidence. Surg. Radiol. Anat. 2020, 42, 835-841. [CrossRef]

58. Lee, L.C.; Genet, M.; Dang, A.B.; Ge, L.; Guccione, J.M.; Ratcliffe, M.B. Applications of Computational Modeling in Cardiac Surgery: Computational Modeling of cardiac mechanics. J. Card. Surg. 2014, 29, 293-302. [CrossRef]

59. Pellikka, P.A.; Arruda-Olson, A.; Chaudhry, F.A.; Chen, M.H.; Marshall, J.E.; Porter, T.R.; Sawada, S.G. Guidelines for Performance, Interpretation, and Application of Stress Echocardiography in Ischemic Heart Disease: From the American Society of Echocardiography. J. Am. Soc. Echocardiogr. 2020, 33, 1-41.e8. [CrossRef] [PubMed]

60. Pasta, S.; Agnese, V.; Di Giuseppe, M.; Gentile, G.; Raffa, G.M.; Bellavia, D.; Pilato, M. In Vivo Strain Analysis of Dilated Ascending Thoracic Aorta by ECG-Gated CT Angiographic Imaging. Ann. Biomed. Eng. 2017, 45, 2911-2920. [CrossRef] [PubMed]

61. Pasta, S.; Gentile, G.; Raffa, G.M.; Scardulla, F.; Bellavia, D.; Luca, A.; Pilato, M.; Scardulla, C. Three-Dimensional Parametric Modeling of Bicuspid Aortopathy and Comparison with Computational Flow Predictions: 3D Anatomic Representations of Bicuspid Aortopathy. Artif. Organs 2017, 41, E92-E102. [CrossRef] [PubMed]

62. Yuen, J. What Is the Role of 3D Printing in Undergraduate Anatomy Education? A Scoping Review of Current Literature and Recommendations. Med. Sci. Educ. 2020, 30, 1321-1329. [CrossRef]

63. Mendonca, D.; Deraje, V.; Gujjalanavar, R.; Gopal, S. Case Series of Three-Dimensional Printing Technology Applied in Complex Craniofacial Deformity Surgery. J. Cleft Lip Palate Craniofac. Anomal. 2016, 3, 88. [CrossRef]

64. Ponomarenko, M.; Ieremeiev, O.; Lukin, V.; Egiazarian, K. An Expandable Image Database for Evaluation of Full-Reference Image Visual Quality Metrics. Electron. Imaging 2020, 2020, 137-1-137-6. [CrossRef]

65. Azer, S.A.; Azer, S. 3D Anatomy Models and Impact on Learning: A Review of the Quality of the Literature. Health Prof. Educ. 2016, 2, 80-98. [CrossRef]

66. Peeler, J.; Bergen, H.; Bulow, A. Musculoskeletal Anatomy Education: Evaluating the Influence of Different Teaching and Learning Activities on Medical Students Perception and Academic Performance. Ann. Anat. Anat. Anz. 2018, 219, 44-50. [CrossRef] [PubMed]

67. Kim, J.W.; Lee, Y.; Seo, J.; Park, J.H.; Seo, Y.M.; Kim, S.S.; Shon, H.C. Clinical Experience with Three-Dimensional Printing Techniques in Orthopedic Trauma. J. Orthop. Sci. 2018, 23, 383-388. [CrossRef]

68. Ben Awadh, A.; Clark, J.; Clowry, G.; Keenan, I.D. Multimodal Three-Dimensional Visualization Enhances Novice Learner Interpretation of Basic Cross-Sectional Anatomy. Anat. Sci. Educ. 2021, ase.2045. [CrossRef] [PubMed]

69. Çeri, N.G. Effect of Non-Cadaveric Methods on the Anatomy Education of Medical Students. Meandros 2021, 22, 105-115. [CrossRef]

70. Hoyek, N.; Rienzo, F.D.; Guillot, A.; Collet, C. The Role of Mental and Motor Processes in Conceiving, Developing and Validating 3D Interactive Human Anatomy Learning Tools. FASEB J. 2020, 34 (Suppl. S1), 1. [CrossRef]

71. Bücking, T.M.; Hill, E.R.; Robertson, J.L.; Maneas, E.; Plumb, A.A.; Nikitichev, D.I. From Medical Imaging Data to 3D Printed Anatomical Models. PLoS ONE 2017, 12, e0178540. [CrossRef]

72. Flaxman, T.E.; Cooke, C.M.; Miguel, O.X.; Sheikh, A.M.; Singh, S.S. A Review and Guide to Creating Patient Specific 3D Printed Anatomical Models from MRI for Benign Gynecologic Surgery. 3D Print. Med. 2021, 7, 17. [CrossRef] [PubMed]

73. Byrne, N.; Velasco Forte, M.; Tandon, A.; Valverde, I.; Hussain, T. A Systematic Review of Image Segmentation Methodology, Used in the Additive Manufacture of Patient-Specific 3D Printed Models of the Cardiovascular System. JRSM Cardiovasc. Dis. 2016, 5, 204800401664546. [CrossRef] [PubMed] 